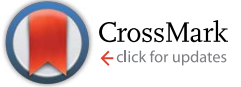

Cite this: Chem. Sci., 2015, 6, 3044

Received 20th January 2015

Accepted 13th March 2015

DOI: $10.1039 / \mathrm{c} 5 \mathrm{sc00221d}$

www.rsc.org/chemicalscience

\title{
Iron(II)-catalyzed asymmetric intramolecular olefin aminochlorination using chloride ion $\uparrow$
}

\author{
Cheng-Liang Zhu, t $^{\mathrm{a}}$ Jun-Shan Tian, t $^{\mathrm{a}}$ Zhen-Yuan Gu, ${ }^{\text {ab }}$ Guo-Wen Xing ${ }^{\mathrm{b}}$ \\ and HaO $\mathrm{Xu}^{* a}$
}

An iron-catalyzed enantioselective and diastereoselective intramolecular olefin aminochlorination reaction is reported (ee up to $92 \%$, dr up to $15: 1$ ). In this reaction, a functionalized hydroxylamine and chloride ion are utilized as nitrogen and chlorine sources, respectively. This new method tolerates a range of synthetically valuable internal olefins that are all incompatible with existing asymmetric olefin aminochlorination methods.

\section{Introduction}

Enantioselective olefin halo-functionalization reactions constitute a range of synthetically valuable yet challenging transformations. ${ }^{1}$ Although a variety of excellent asymmetric olefin halo-oxygenation reactions have been discovered, ${ }^{2}$ there are much fewer asymmetric olefin aminohalogenation methods available. ${ }^{3}$ In particular, there have been just a few reported catalytic asymmetric olefin aminochlorination reactions. ${ }^{4}$ In one instance, Feng discovered the chiral Lewis acid-catalyzed aminochlorination of chalconic and other $\alpha, \beta$-unsaturated olefins. ${ }^{4 a, c}$ Also, Chemler reported copper-catalyzed aminochlorination of terminal olefins with chlorine radical donors in the presence of $\mathrm{MnO}_{2}$ (Scheme 1A). ${ }^{4 b}$ Despite these and other important discoveries, catalytic asymmetric aminochlorination methods for internal, non-chalconic olefins have yet to be developed. These methods would be synthetically valuable because they would readily provide vicinal amino chlorides, a class of important chiral building blocks. Moreover, asymmetric olefin aminochlorination that proceeds through an ironnitrenoid intermediate has not yet been reported. ${ }^{5}$

We previously discovered $\mathrm{Fe}\left(\mathrm{BF}_{4}\right)_{2}$-based catalysts for both diastereoselective and enantioselective intramolecular olefin aminofluorination reactions. ${ }^{6}$ Our initial attempts to apply these catalysts to olefin aminochlorination reactions led to either low diastereoselectivity or low yield, presumably due to the reason that chlorine and fluorine atom-transfer may proceed through

${ }^{a}$ Department of Chemistry, Georgia State University, 100 Piedmont Avenue SE, Atlanta, Georgia, 30303, USA. E-mail: hxu@gsu.edu; Fax: +1-404-413-5505; Tel: +1-404-4135553

${ }^{b}$ Department of Chemistry, Beijing Normal University, Beijing, 100875, China

$\dagger$ Electronic supplementary information (ESI) available: Experimental procedure, characterization data for all new compounds, selected NMR spectra and HPLC traces. CCDC 1041826. For ESI and crystallographic data in CIF or other electronic format see DOI: 10.1039/c5sc00221d

\$ These authors contributed equally. distinct mechanisms. Therefore, we explored a range of activating group-ligand combinations and discovered entirely new catalytic conditions for asymmetric olefin aminochlorination. Herein, we describe iron-catalyzed enantioselective and diastereoselective intramolecular aminochlorination for a range of internal, non-chalconic olefins (ee up to $92 \%$, dr up to $15: 1$ ). In these reactions, a functionalized hydroxylamine and chloride ion were utilized as nitrogen and chlorine sources, respectively. This method tolerates a range of synthetically valuable internal olefins that are all incompatible with existing asymmetric olefin aminochlorination approaches; it also provides a new approach that is complementary to known methods for the asymmetric synthesis of amino chlorides with contiguous stereogenic centers.

Prior to this research, Bach reported an $\mathrm{FeCl}_{2}$-catalyzed racemic intramolecular olefin aminochlorination method using acyl azides, TMSCl, and EtOH under ligand-free conditions. ${ }^{7}$
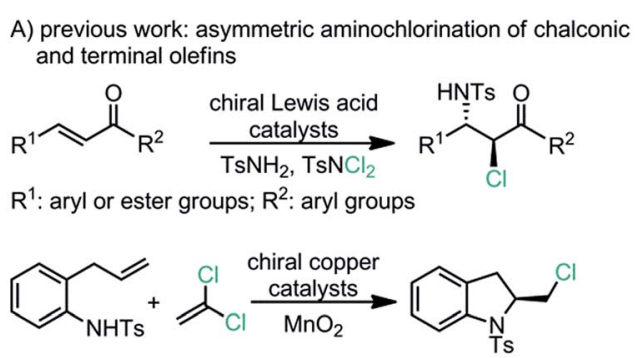

B) current work: iron-catalyzed asymmetric aminochlorination of internal olefins with chloride ion

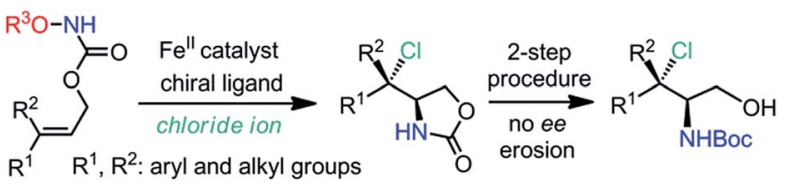

Scheme 1 Catalytic asymmetric olefin aminochlorination: summary of this work and other existing asymmetric methods. 
Table 1 Catalyst discovery for the iron-catalyzed diastereoselective olefin aminochlorination reaction

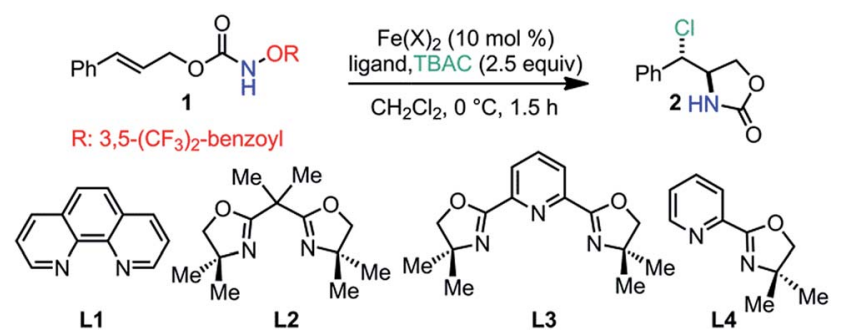

\begin{tabular}{|c|c|c|c|c|c|}
\hline Entry $^{a}$ & $\mathrm{Fe}(\mathrm{X})_{2}$ & Ligand (mol\%) & Conversion $^{b}$ & Yield $^{c}$ & $\mathrm{dr}^{b}$ (anti : syn) \\
\hline 1 & $\mathrm{FeCl}_{2}$ & None & $62 \%$ & $45 \%$ & $2: 1$ \\
\hline 2 & $\mathrm{FeCl}_{2}$ & L1 (20) & $>95 \%$ & $80 \%$ & $>20: 1$ \\
\hline 4 & $\mathrm{Fe}\left(\mathrm{NTf}_{2}\right)_{2}$ & L2 (10) & $>95 \%$ & $82 \%$ & $0.83: 1$ \\
\hline 5 & $\mathrm{Fe}\left(\mathrm{NTf}_{2}\right)_{2}$ & L3 (10) & $61 \%$ & $34 \%$ & $0.25: 1$ \\
\hline 6 & $\mathrm{Fe}\left(\mathrm{NTf}_{2}\right)_{2}$ & L4 (20) & $>95 \%$ & $75 \%$ & $1.8: 1$ \\
\hline
\end{tabular}

${ }^{a}$ Unless stated otherwise, the reactions were carried out under a nitrogen atmosphere. TBAC: tetra- $n$-butylammonium chloride. ${ }^{b}$ Conversion and dr were determined by ${ }^{1} \mathrm{H}$ NMR. ${ }^{c}$ Isolated yield.

Excellent syn-selectivity was observed with styrenyl olefins (dr up to > 20:1). However, poor diastereoselectivity was recorded with non-styrenyl acyclic olefins (dr: $1: 1)$. The new method presented here has a few unique features which complement the existing iron-catalyzed olefin aminochlorination method. First, excellent anti-selectivity has been observed across a wide range of styrenyl and non-styrenyl olefins. Second, good to excellent enantioselectivity has been achieved with a variety of internal, non-chalconic olefins (ee up to $92 \%$ ). Finally, acyl azides are non-reactive under the described reaction conditions (vide infra), which suggests that iron-nitrenoid generation may proceed via different pathways compared with the known azide activation pathway.

\section{Results and discussion}

A cinnamyl alcohol-derived acyloxyl carbamate $\mathbf{1}$ was selected as the model substrate for catalyst discovery (Table 1$) \cdot{ }^{8}$ In the presence of tetra- $n$-butylammonium chloride (TBAC), we observed that $\mathrm{FeCl}_{2}$ alone catalyzed a sluggish reaction under ligand-free conditions (entry $1,45 \%$ yield, dr: $2: 1$ ). ${ }^{9}$ However, the $\mathrm{FeCl}_{2}$-phenanthroline (L1) complex catalyzed the anti-

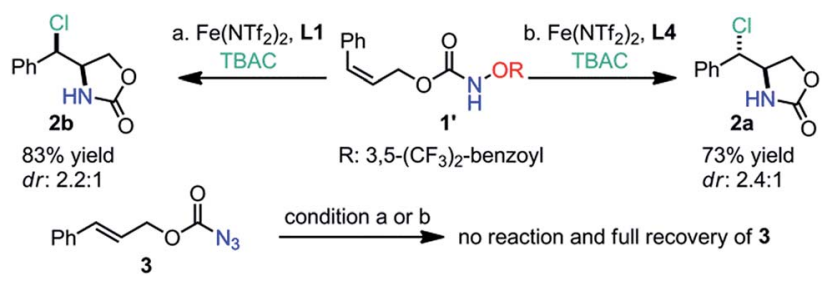

Scheme 2 Iron-catalyzed aminochlorination with a cis olefin and an acyl azide. ${ }^{a}$ Reaction conditions: Fe(NTf $)_{2}$ (10 mol\%), L1 (20 mol\%), TBAC (2.5 equiv.), $\mathrm{CH}_{2} \mathrm{Cl}_{2}, 0{ }^{\circ} \mathrm{C}, 2$ h. ${ }^{b}$ Reaction conditions: Fe $\left(\mathrm{NTf}_{2}\right)_{2}$ (10 mol\%), L4 (20 mol\%), TBAC (2.5 equiv.), $\mathrm{CH}_{2} \mathrm{Cl}_{2}, \mathrm{O}^{\circ} \mathrm{C}, 2 \mathrm{~h}$.
Table 2 Substrate scope of the iron-catalyzed diastereoselective olefin aminochlorination reaction

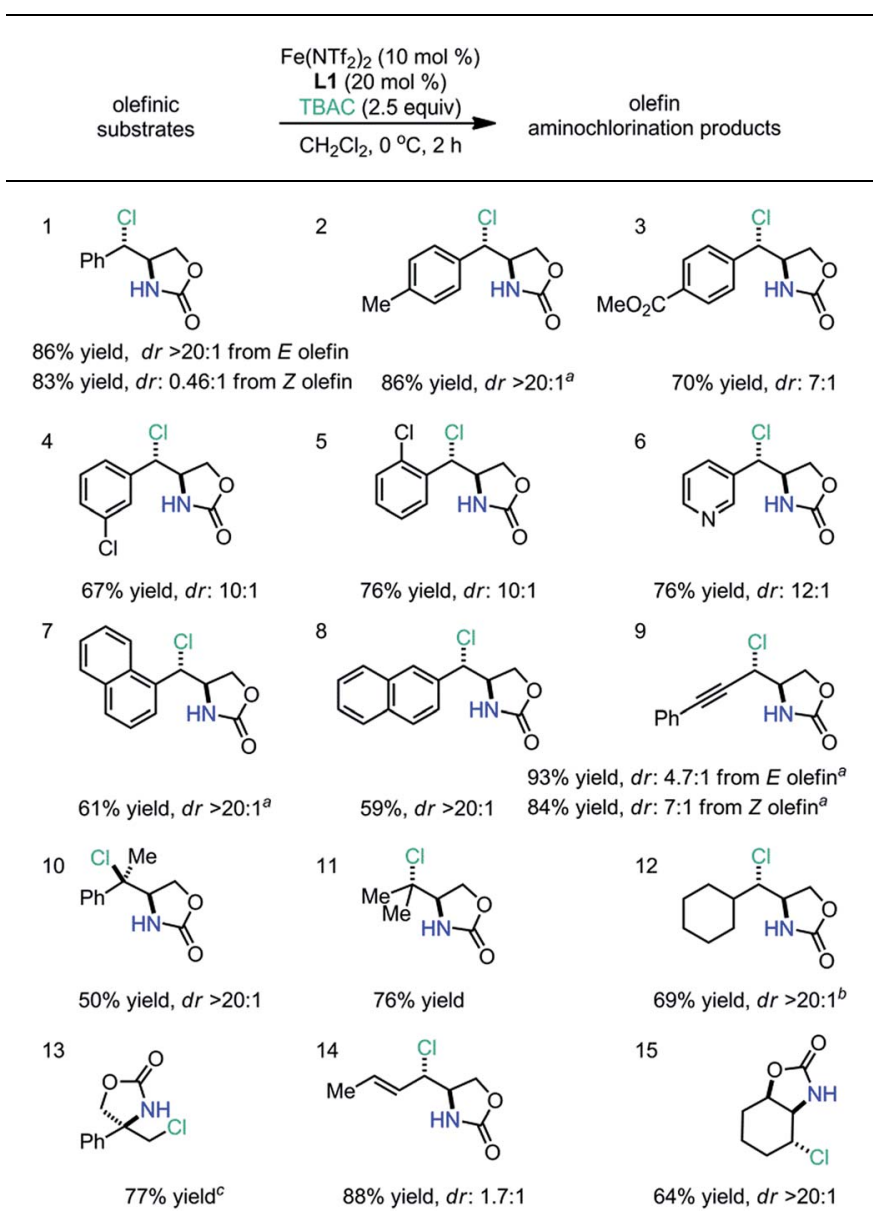

${ }^{a}$ Reaction conditions: $-15{ }^{\circ} \mathrm{C}, 2 \mathrm{~h} .{ }^{b}$ Reaction conditions: $0{ }^{\circ} \mathrm{C}, 5 \mathrm{~h}$. ${ }^{c}$ Reaction conditions: $0{ }^{\circ} \mathrm{C}, 12 \mathrm{~h}$. 
aminochlorination with significantly improved yield and $\mathrm{dr}$ (entry 2, 80\% yield, $\mathrm{dr}>20: 1$ ). We also noted that the $\mathrm{Fe}\left(\mathrm{NTf}_{2}\right)_{2}-\mathbf{L 1}$ complex provided essentially the same reactivity and diastereoselectivity (entry 3, 86\% yield, dr $>20: 1$ ). Interestingly, the $\mathrm{Fe}\left(\mathrm{NTf}_{2}\right)_{2}$-bisoxazoline (L2) complex resulted in a loss of diastereoselectivity (entry $4,82 \%$ yield, dr: $0.83: 1$ ). Furthermore, the $\mathrm{Fe}\left(\mathrm{NTf}_{2}\right)_{2}-\mathbf{L} \mathbf{3}$ complex promoted the synaminochlorination with moderate yield and dr (entry 5, 34\% yield, dr: $0.25: 1)$. We also observed that the $\mathrm{Fe}\left(\mathrm{NTf}_{2}\right)_{2}-\mathbf{L 4}$ complex catalyzed the anti-aminochlorination with a modest $\mathrm{dr}$ (entry 6, 75\% yield, dr: $1.8: 1$ ). Notably, an iron-L4 complex resulted in high $\mathrm{dr}$ and reaction rate in the previously reported olefin aminofluorination reaction. ${ }^{6}$ These observations suggest that ligands are involved in the diastereoselectivity-determining step and provide excellent opportunities for diastereo-control.

The observed ligand-enabled diastereo-control with transolefin 1 prompted us to evaluate cis-olefin $\mathbf{1}^{\prime}$ (Scheme 2). To our surprise, the $\mathrm{Fe}\left(\mathrm{NTf}_{2}\right)_{2}-\mathbf{L 1}$ complex catalyzed syn-aminochlorination, while the $\mathrm{Fe}\left(\mathrm{NTf}_{2}\right)_{2}-\mathbf{L 4}$ complex promoted antiaminochlorination with essentially the same $\mathrm{dr}$ (Scheme 2). The different reaction profiles for isomeric olefins $\mathbf{1}$ and $\mathbf{1}^{\prime}$ suggest that the aminochlorination reaction is neither stereospecific nor fully stereo-convergent, which is significantly different from the iron-catalyzed olefin aminofluorination reaction. ${ }^{6}$

Furthermore, an acyl azide 3 was evaluated under the reaction conditions as a control experiment. Interestingly, the acyl azide 3 was fully recovered and no aminochlorination product was detected. These results suggest that the activation of acyloxyl carbamates ( $\mathbf{1}$ and $\mathbf{1}^{\prime}$ ) may proceed via different pathways compared with the known azide activation pathway. ${ }^{7}$

We subsequently explored a range of olefins under the optimized conditions to evaluate the scope and limitations of this anti-aminochlorination method (Table 2). We discovered that di-substituted styrenyl olefins are generally good substrates; both electron-donating and electron-withdrawing substituents are compatible with this method (entries 1-4). Importantly, ortho-substituents and pyridyl groups are both tolerated (entries 5-6). Furthermore, extended aromatics, including naphthyl olefins, are reasonable substrates (entries 7-8). Moreover, isomeric ene-ynes are both excellent substrates for the stereo-convergent and anti-selective method (entry 9). Additionally, we observed that both styrenyl and non-styrenyl tri-substituted olefins undergo aminochlorination smoothly with excellent $\mathrm{dr}$ (entries 10-11). ${ }^{10}$ We also discovered that a cyclohexyl-substituted olefin was an excellent substrate (entry 12, $\mathrm{dr}>20: 1)$. Further exploration revealed that both 1,1-disubstituted olefins and dienes are viable substrates with excellent regioselectivity (entries 13-14). Most notably, a cyclic olefin could also undergo highly diastereoselective anti-aminochlorination (entry 15, $\mathrm{dr}>20: 1$ ), yielding a product which is difficult to obtain with known methods. ${ }^{11}$ Since the $\mathrm{FeCl}_{2}-\mathbf{L 1}$ complex provides essentially the same $\mathrm{dr}$ and yield in these diastereoselective reactions, $\mathrm{FeCl}_{2}$ can be a convenient substitute for $\mathrm{Fe}\left(\mathrm{NTf}_{2}\right)_{2}$ in racemic reactions.

Table 3 Catalyst discovery for the iron-catalyzed asymmetric olefin aminochlorination reaction

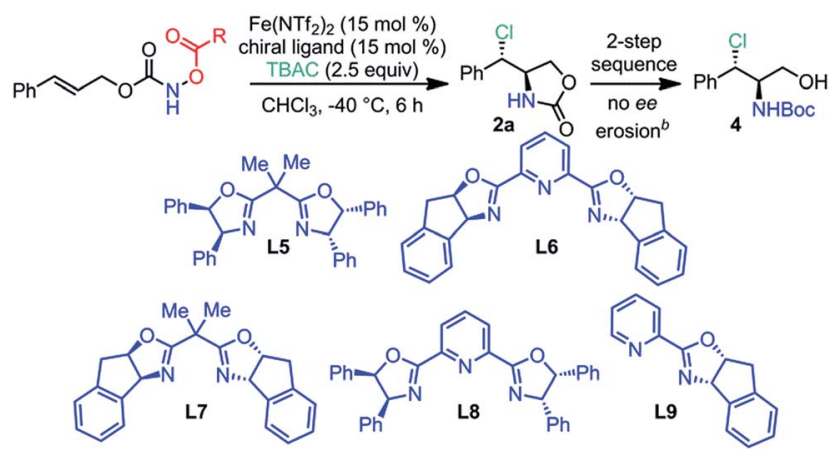

\begin{tabular}{|c|c|c|c|c|c|c|c|}
\hline Entry $^{a}$ & $\mathrm{R}$ & Ligand & Conversion $^{c}$ & Yield $^{d}$ & $\mathrm{dr}^{c}$ (anti : syn) & $\mathrm{ee}^{e}$ (anti) & $\mathrm{ee}^{e}(\mathrm{syn})$ \\
\hline 1 & $3,5-\left(\mathrm{CF}_{3}\right)_{2}-\mathrm{Ph}$ & L5 & $>95 \%$ & $53 \%$ & $9.9: 1$ & $84 \%$ & $<5 \%$ \\
\hline 2 & $3,5-\left(\mathrm{CF}_{3}\right)_{2}-\mathrm{Ph}$ & L6 & $>95 \%$ & $68 \%$ & $0.5: 1$ & $24 \%$ & $79 \%$ \\
\hline 3 & $3,5-\left(\mathrm{CF}_{3}\right)_{2}-\mathrm{Ph}$ & L7 & $88 \%$ & $61 \%$ & $1.7: 1$ & $<5 \%$ & $<5 \%$ \\
\hline 4 & $3,5-\left(\mathrm{CF}_{3}\right)_{2}-\mathrm{Ph}$ & L8 & $>95 \%$ & $32 \%$ & $2.5: 1$ & $47 \%$ & $30 \%$ \\
\hline 5 & $3,5-\left(\mathrm{CF}_{3}\right)_{2}-\mathrm{Ph}$ & L9 & $>95 \%$ & $82 \%$ & $0.5: 1$ & $8 \%$ & $24 \%$ \\
\hline $6^{f}$ & $3,5-\left(\mathrm{CF}_{3}\right)_{2}-\mathrm{Ph}$ & L5 & $>95 \%$ & $51 \%$ & $11.0: 1$ & $90 \%$ & $<5 \%$ \\
\hline $7^{f}$ & $\mathrm{CH}_{3}$ & L5 & $>95 \%$ & $42 \%$ & $1.1: 1$ & $97 \%$ & $<5 \%$ \\
\hline $8^{f}$ & $\mathrm{CH}_{2} \mathrm{Cl}$ & L5 & $>95 \%$ & $67 \%$ & $9.6: 1$ & $89 \%$ & $<5 \%$ \\
\hline $9^{f, g}$ & $\mathrm{CH}_{2} \mathrm{Cl}$ & L5 & $>95 \%$ & $58 \%$ & $9.0: 1$ & $83 \%$ & $<5 \%$ \\
\hline
\end{tabular}

${ }^{a}$ Unless stated otherwise, the reactions were carried out under a nitrogen atmosphere with $4 \AA$ molecular sieves. ${ }^{b}$ Reaction conditions: Boc ${ }_{2} \mathrm{O}$, $\mathrm{Et}_{3} \mathrm{~N}$, DMAP; then $\mathrm{Cs}_{2} \mathrm{CO}_{3}$, MeOH, 85\% over two steps; see ESI for details. ${ }^{c}$ Conversion and dr were determined by ${ }^{1} \mathrm{H}$ NMR. ${ }^{d}$ Isolated yield. ${ }^{e}$ Enantiomeric excess (ee) was measured by HPLC with chiral columns; the absolute stereochemistry was determined by X-ray crystallographic

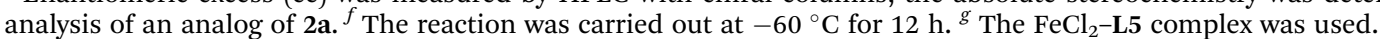


In order to fulfil the need for catalytic asymmetric olefin aminochlorination, we further explored asymmetric induction for internal, non-chalconic olefins with a variety of iron-chiral ligand complexes (Table 3) ${ }^{12}$ First, we discovered that the ironL5 complex induced diastereoselective and enantioselective anti-aminochlorination, albeit with a low yield, mostly due to the competing aminohydroxylation reaction (entry $1,53 \%$ yield, dr: $9.9: 1)$. Interestingly, the anti-addition product $2 \mathrm{a}$ was obtained with excellent ee ( $84 \%$ ee), while the syn-addition product $2 \mathbf{b}$ was obtained essentially as a racemate $\left(<5 \%\right.$ ee). ${ }^{13}$ Additionally, a two-step procedure can convert 2a to a chlorinated amino alcohol triad 4 without ee erosion. ${ }^{14}$ Next, we observed that the iron-L6 complex induced moderately diastereoselective syn-aminochlorination (entry 2, 68\% yield, dr: $0.48: 1)$. To our surprise, the anti-addition product $2 \mathrm{a}$ was obtained with moderate ee $(24 \%$ ee), while the syn-addition product $2 \mathbf{b}$ was isolated with significant ee $(79 \%$ ee). Furthermore, we evaluated chiral ligands $\mathbf{L} 7$ and $\mathbf{L 8}$ and determined that they are less effective for asymmetric induction (entries 3-4). Additionally, chiral ligand $\mathbf{L 9}$ induced fast yet non-selective aminochlorination with a high overall yield (entry 5$).{ }^{15}$ With the iron-L5 complex in hand, we subsequently explored other reaction parameters. First, a decreased reaction temperature was found to benefit both dr and ee (entry 6, dr: $11: 1$ and 90\% ee for $2 \mathrm{a}$ at $-60{ }^{\circ} \mathrm{C}$ ). Next, replacing the 3,5-bis(trifluoromethyl) benzoyl activating group with a smaller acetyl group further enhanced the ee (entry 7, 97\% ee for 2a); however, much lower $\mathrm{dr}$ and yield were obtained (entry 7, dr: $1.1: 1,42 \%$ yield). Finally, a chloroacetyl activating group induced an effective balance between overall yield and stereoselectivity (entry 8, 67\% yield, dr: $9.6: 1$ and $89 \%$ ee for $2 a$ ). We also observed that the $\mathrm{FeCl}_{2}-\mathbf{L} \mathbf{5}$ complex induced a slightly less selective reaction with a lower yield (entry 9, 58\% yield, dr: $9.0: 1$ and $83 \%$ ee for 2 a).

In order to evaluate the scope of this asymmetric method, we explored the asymmetric induction with a range of internal olefins (Table 4). The chiral catalyst provides excellent asymmetric induction with styrenyl olefins. A range of parasubstituted styrenyl olefins with different electronic properties were converted to the corresponding aminochlorination products with high dr and ee (entries 1-6, dr: 9.6-15:1, ee: 86-91\%). Additionally, meta-substituted styrenyl olefins are also good substrates but with slightly decreased ee (entries 7-9, dr: $10-15: 1$, ee: $80-87 \%)$. However, we discovered that ortho-substitution of styrenes has a deleterious effect on ee (entries 10-11, dr: 4.5-12:1, ee: 77-79\%). Interestingly, both $\alpha$ - and $\beta$-naphthyl olefins are excellent substrates (entries 12-13, dr: 4.5-10 : 1, ee: 89-92\%). To our delight, a 3-pyridyl olefin with a basic nitrogen atom is a reasonable substrate for the asymmetric aminochlorination (entry 14, dr: $1.8: 1$, ee: $70 \%$ for the anti-diastereomer). Moreover, we observed that the iron-L5 complex can induce significant ee in the aminochlorination with non-styrenyl olefins (entry $15, \mathrm{dr}: 2: 1$, ee: $54 \%$ for the anti-diastereomer). To our surprise, the iron-L6 complex proved to be uniquely effective for the asymmetric induction with tri-substituted olefins, while the iron-L5 complex was less effective (entry 16, dr: $2.3: 1$, ee: $86 \%$ for the anti-diastereomer). ${ }^{16}$
Table 4 Substrate scope for the iron-catalyzed asymmetric olefin aminochlorination reaction

\begin{tabular}{|c|c|c|}
\hline \multirow{2}{*}{$\begin{array}{c}\text { olefinic } \\
\text { substrates }^{a}\end{array}$} & $\begin{array}{c}\mathrm{Fe}\left(\mathrm{NTf}_{2}\right)_{2}(15 \mathrm{~mol} \%) \\
\text { L5 }(15 \mathrm{~mol} \%) \\
\stackrel{\operatorname{TBAC}(2.5 \text { equiv })}{\longrightarrow}\end{array}$ & \multirow{2}{*}{$\begin{array}{l}\text { olefin } \\
\text { aminochlorination products }\end{array}$} \\
\hline & $\mathrm{CHCl}_{3},-60^{\circ} \mathrm{C}, 12 \mathrm{~h}$ & \\
\hline
\end{tabular}
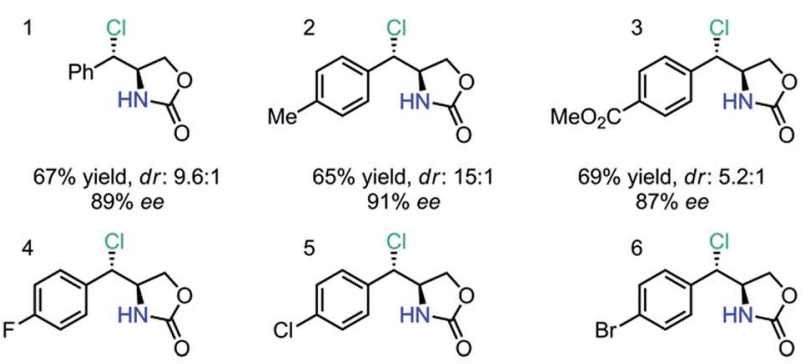

$69 \%$ yield, $d r: 5.2: 1$

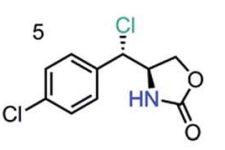

$84 \%$ yield, $d r: 12: 1$
$90 \%$ ee

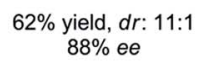

$87 \%$ ee

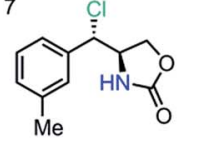

8
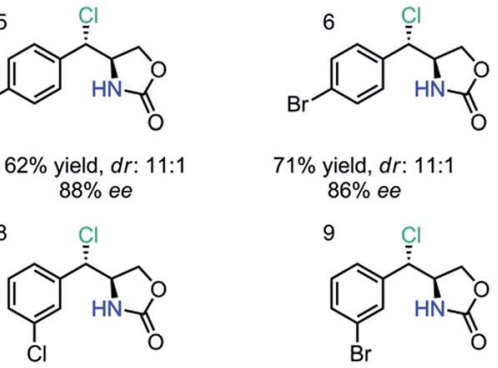

$71 \%$ yield, $d r: 11: 1$

$86 \%$ ee

9

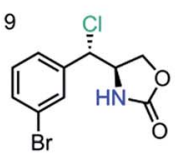

$75 \%$ yield, $d r: 12: 1$

10
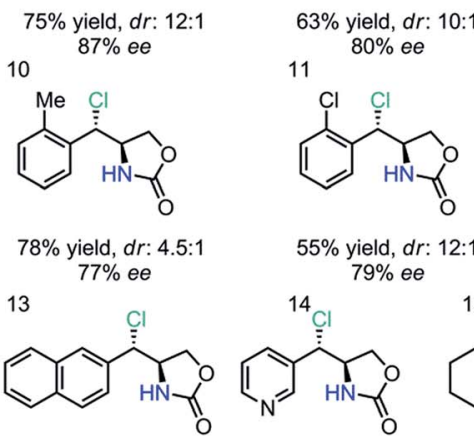

$55 \%$ yield, $d r: 12:$
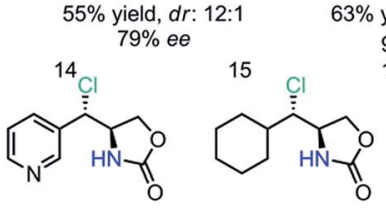

$71 \%$ yield, $d r: 15: 1$

$80 \%$ ee

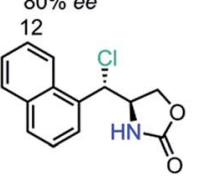

$53 \%$ yield, $d r: 4.5: 1$ $89 \% e e^{b}$

$51 \%$ yield, $d r: 1.8: 1$ $70 \%$ ee

$6 \%$ yield, $d r:$
$54 \%$ ee

$\%$ yield, $d r: 10: 1$ $92 \% e e^{b}$

16

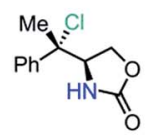

2.3:1

${ }^{a}$ Unless stated otherwise, mono-chloroacetyl was selected as the activating group for asymmetric catalysis; the ee for all synaminochlorination products was less than $5 \% .{ }^{b} \mathrm{Bis}$ (trifluoromethyl)benzoyl was selected as the activating group. ${ }^{c}$ The ee for the synaddition product was $12 \%$. ${ }^{d}$ L6 was used as the ligand for asymmetric induction; the ee for the syn-addition product was $50 \%$.

During the exploration of substrate scope, it was surprising to observe completely different ee values for anti- and syn-diastereomers (e.g. 2a and $\mathbf{2 b}$ ). In contrast, exactly the same ee for both diastereomeric products was observed in the iron-catalyzed aminofluorination of $1 .^{6}$ In order to obtain greater mechanistic insights, we carried out ee analysis for all isolable products using several control experiments (Scheme 3). First, in an $\mathrm{Fe}\left(\mathrm{NTf}_{2}\right)_{2}$-catalyzed reaction with trans-olefin 1, two aminochlorination products were obtained (Scheme $3 \mathrm{~A}, 90 \%$ ee for $2 \mathrm{a}$, $<5 \%$ ee for $2 \mathbf{b}$, dr: $11: 1) .{ }^{17}$ Simultaneously, diastereomers $5 \mathbf{a}$ and $\mathbf{5 b}$ were also isolated with the same ee as two competing olefin aminohydroxylation products (Scheme $3 \mathrm{~A}, 88 \%$ ee for $\mathbf{5 a}$ and 5b, dr: $4: 1$ ). However, completely different selectivity (both $\mathrm{dr}$ and ee) was observed in an $\mathrm{Fe}\left(\mathrm{NTf}_{2}\right)_{2}$-catalyzed reaction with cis-olefin $\mathbf{1}^{\prime}$ (Scheme $3 \mathrm{~A}, 85 \%$ ee for $\mathbf{2 a}$ and $31 \%$ ee for $\mathbf{2 b}$, dr: 
A) $\mathrm{Fe}(\mathrm{NTf})_{2}$-catalyzed asymmetric aminochlorination and aminohydroxylation with isomeric olefins
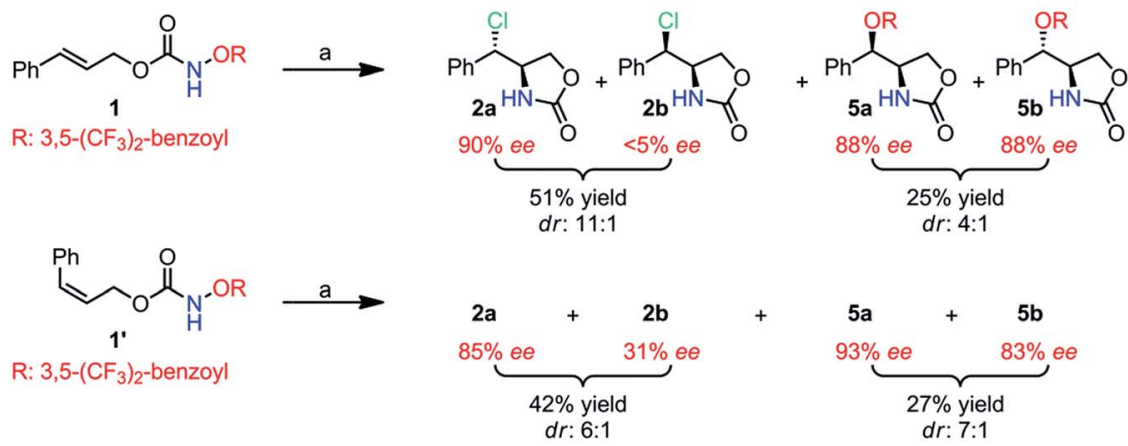

B) control experiments to detect the acceleration effect of chloride ion

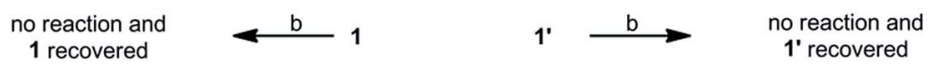

C) $\mathrm{FeCl}_{2}$-catalyzed and mediated asymmetric olefin aminochlorination reactions

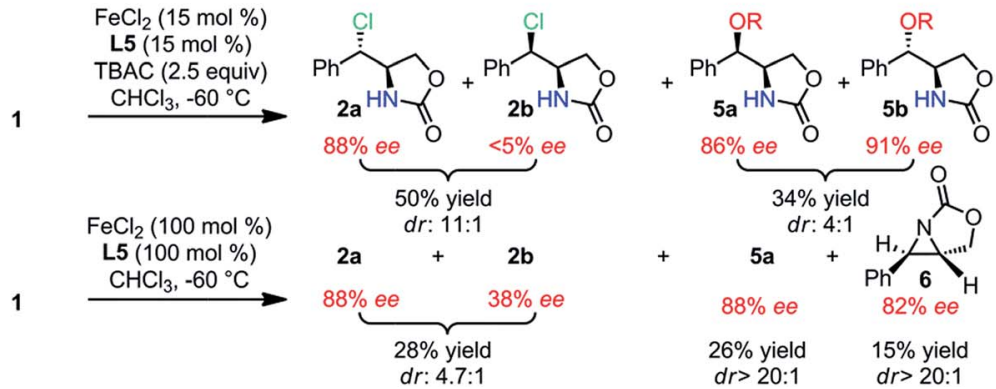

Scheme 3 Control experiments to probe the mechanism. ${ }^{a}$ Reaction conditions: Fe( $\left.\mathrm{NTf}_{2}\right)_{2}(15 \mathrm{~mol} \%), \mathrm{L} 1$ (15 mol\%), TBAC (2.5 equiv.), CHCl 3 , $-60{ }^{\circ} \mathrm{C}, 12$ h. ${ }^{b}$ Reaction conditions: Fe(NTf $)_{2}(15 \mathrm{~mol} \%), \mathrm{L} 1(15 \mathrm{~mol} \%), \mathrm{CHCl}_{3},-60{ }^{\circ} \mathrm{C}, 12 \mathrm{~h}$.

$6: 1 ; 93 \%$ ee for $5 \mathbf{a}$ and $83 \%$ ee for $\mathbf{5 b}, \mathrm{dr}: 7: 1)$. In both cases, $\mathbf{5 a}$ and $\mathbf{5 b}$ cannot be converted to $\mathbf{2 a}$ under the reaction conditions.

These observations provide several important mechanistic insights. First, the non-stereospecificity observed in the ironcatalyzed olefin aminochlorination suggests that the formation of $\mathrm{C}-\mathrm{N}$ and $\mathrm{C}-\mathrm{Cl}$ bonds occurs in a stepwise fashion. ${ }^{18}$ Second, the lack of complete stereo-convergence between the reaction profiles of isomeric olefins ( $\mathbf{1}$ and $\mathbf{1}^{\prime}$ ) suggests that $\mathrm{C}-\mathrm{N}$ bond formation may be the rate- and ee-determining step. $^{\mathbf{1 8}}$ Furthermore, since essentially the same ee was observed for $\mathbf{2 a}$, $\mathbf{5 a}$, and $\mathbf{5 b}$ from the reaction with trans-olefin $\mathbf{1}$, it is likely that these products are derived from the same intermediate after the ee-determining step. Additionally, the fact that the syn-aminochlorination product $\mathbf{2 b}$ was isolated as a racemate suggests that $\mathbf{2 b}$ may be derived from non-stereoselective pathways which are distinct from the one leading to the formation of $\mathbf{2 a}$, $\mathbf{5 a}$, and $\mathbf{5 b}$.

The product divergence ( $\mathbf{2} \mathbf{a}$ vs. $\mathbf{5 a} / \mathbf{b}$ ) after the ee-determining step is mechanistically interesting. Therefore, we studied the effect of external chloride ion. To our surprise, in the absence of TBAC, the $\mathrm{Fe}\left(\mathrm{NTf}_{2}\right)_{2}-\mathbf{L 5}$ complex alone was ineffective for the nitrogen atom-transfer at $-60{ }^{\circ} \mathrm{C} ; \mathbf{1}$ and $\mathbf{1}^{\prime}$ were both fully recovered (Scheme 3B). However, aminochlorination occurred as soon as a stoichiometric amount of TBAC was introduced. This observation suggests that the $\mathrm{Fe}\left(\mathrm{NTf}_{2}\right)_{2}-\mathbf{L} \mathbf{5}$ complex may serve as a pre-catalyst and it may be activated by chloride ion in situ.

In order to test this hypothesis, we further carried out the $\mathrm{FeCl}_{2}$-catalyzed reaction in the presence of TBAC (Scheme 3C). Notably, 2a was isolated with essentially the same ee as that obtained under the standard conditions ( $88 \%$ ee for 2 a and $<5 \%$

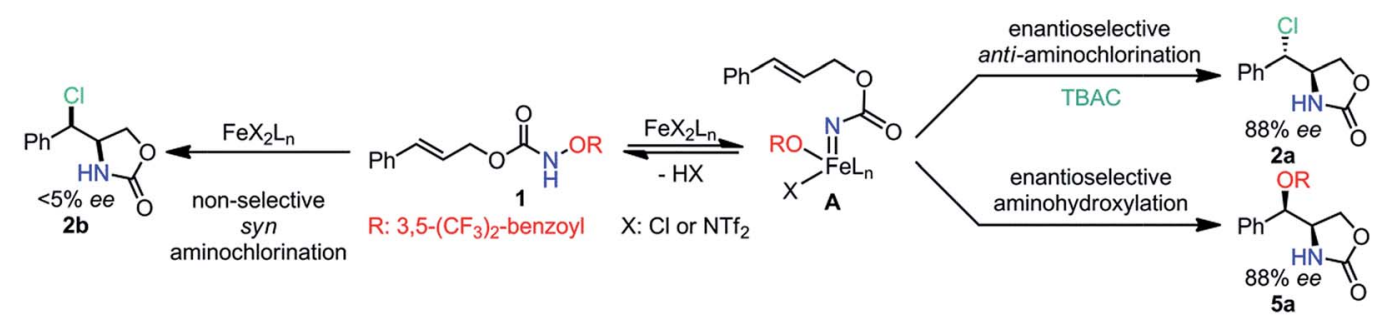

Scheme 4 Proposed mechanistic working hypothesis for the iron-catalyzed asymmetric aminochlorination of trans-olefin 1. 
ee for $\mathbf{2 b}$ ). This result suggests that the catalytically relevant species may also be generated from the $\mathrm{FeCl}_{2}-\mathbf{L 5}$ complex.

To probe for more mechanistic details, we subsequently carried out the $\mathrm{FeCl}_{2}$-promoted olefin aminochlorination in the absence of TBAC (100 mol\% $\mathrm{FeCl}_{2}, 100 \mathrm{~mol} \% \mathrm{L5}$, Scheme 3C). Under these conditions, $\mathrm{FeCl}_{2}$ is the only available chlorine source. Surprisingly, we discovered that 2 a was obtained with essentially the same ee compared with the two previous control experiments (88\% ee for 2a). Furthermore, a syn-aminohydroxylation product 5a was isolated with excellent $\mathrm{dr}$ and ee (dr $>20: 1,88 \%$ ee). These observations suggest that $\mathrm{Fe}-\mathrm{Cl}$ bond cleavage may be relevant for the chlorine atom-transfer step during the enantioselective anti-aminochlorination. ${ }^{19}$ In addition, we also identified a small amount of aziridine 6 (15\% yield, $82 \%$ ee), and further discovered that it could not be converted to either $\mathbf{2 a}$ or $5 \mathbf{a}$ under the reaction conditions.

With the accumulated mechanistic evidence, we propose a plausible mechanistic working hypothesis for the iron-catalyzed asymmetric aminochlorination of trans-olefin 1 (Scheme 4). First, the iron catalyst reversibly cleaves the $\mathrm{N}-\mathrm{O}$ bond in the acyloxyl carbamate 1, generating iron-nitrenoid $\mathbf{A}$ with chloride as a counter ion. From there, A may participate in enantioselective and diastereoselective aminochlorination and aminohydroxylation to afford $\mathbf{2 a}$ and $\mathbf{5 a}$, respectively. Since the aminochlorination-aminohydroxylation competition occurs after the ee-determining step, $2 \mathbf{a}$ is obtained with essentially the same ee as 5a. At the same time, $\mathbf{1}$ may be converted to $2 \mathbf{b}$ via a non-stereoselective pathway which is distinct from the one leading to the formation of $\mathbf{2 a}$ and 5a. Further mechanistic studies are required to elucidate the details.

\section{Conclusions}

In conclusion, we have described an iron-catalyzed enantioselective and diastereoselective aminochlorination method for internal, non-chalconic olefins. This method tolerates a range of synthetically valuable olefins that are all incompatible with existing asymmetric olefin aminochlorination methods. It also provides a complementary approach for the asymmetric synthesis of amino chlorides with contiguous stereogenic centers. Our preliminary mechanistic studies revealed that an $\mathrm{FeCl}_{2}$-derived nitrenoid may be a feasible reactive intermediate and that $\mathrm{Fe}-\mathrm{Cl}$ bond cleavage may be relevant for stereoselective chlorine atom-transfer. Our current efforts are focused on the mechanistic investigation of this new reaction and method development for the enantioselective intermolecular olefin aminochlorination.

\section{Acknowledgements}

This work was supported by the National Institutes of Health (GM110382) and Georgia State University. Z.-Y. G. was supported by NSFC (21272027) and a fellowship from China Scholarship Council.

\section{Notes and references}

1 For selected reviews of asymmetric olefin halofunctionalization, see: (a) S. E. Denmark, W. E. Kuester and M. T. Burk, Angew. Chem., Int. Ed., 2012, 51, 10938; (b) S. R. Chemler and M. T. Bovino, ACS Catal., 2013, 3, 1076; (c) S. A. Snyder, D. S. Treitler and A. P. Brucks, Aldrichimica Acta, 2011, 44, 27.

2 For selected reports on catalytic asymmetric olefin halooxygenation, see: (a) S. H. Kang, S. B. Lee and C. M. Park, J. Am. Chem. Soc., 2003, 125, 15748; (b) G. E. Veitch and E. N. Jacobsen, Angew. Chem., Int. Ed., 2010, 49, 7332; (c) W. Zhang, S. Zheng, N. Liu, J. B. Werness, I. A. Guzei and W. Tang, J. Am. Chem. Soc., 2010, 132, 3664; (d) L. Zhou, C. K. Tan, X. Jiang, F. Chen and Y.-Y. Yeung, J. Am. Chem. Soc., 2010, 132, 15474; (e) K. Murai, T. Matsushita, A. Nakamura, S. Fukushima, M. Shimura and H. Fujioka, Angew. Chem., Int. Ed., 2010, 49, 9174; (f) S. E. Denmark and M. T. Burk, Org. Lett., 2012, 14, 256; $(g)$ D. Huang, H. Wang, F. Xue, H. Guan, L. Li, X. Peng and Y. Shi, Org. Lett., 2011, 13, 6350; (h) R. Yousefi, D. C. Whitehead, J. M. Mueller, R. J. Staples and B. Borhan, Org. Lett., 2011, 13, 608; (i) R. Yousefi, K. D. Ashtekar, D. C. Whitehead, J. E. Jackson and B. Borhan, J. Am. Chem. Soc., 2013, 135, 14524; (j) D. H. Paull, C. Fang, J. R. Donald, A. D. Pansick and S. F. Martin, J. Am. Chem. Soc., 2012, 134, 11128; (k) M. C. Dobish and J. N. Johnston, J. Am. Chem. Soc., 2012, 134, 6068; (l) Y.-M. Wang, J. Wu, C. Hoong, V. Rauniyar and F. D. Toste, J. Am. Chem. Soc., 2012, 134, 12928; (m) V. Rauniyar, A. D. Lackner, G. L. Hamilton and F. D. Toste, Science, 2011, 334, 1681; (n) T. Honjo, R. J. Phipps, V. Rauniyar and F. D. Toste, Angew. Chem., Int. Ed., 2012, 51, 9684; (o) J. Wu, Y.-M. Wang, A. Drljevic, V. Rauniyar, R. J. Phipps and F. D. Toste, Proc. Natl. Acad. Sci. U. S. A., 2013, 110, 13729; ( $p)$ H. Nakatsuji, Y. Sawamura, A. Sakakura and K. Ishihara, Angew. Chem., Int. Ed., 2014, 53, 6974; (q) L. Li, C. Su, X. Liu, H. Tian and Y. Shi, Org. Lett., 2014, 16, 3728.

3 For selected reports on catalytic asymmetric olefin aminobromination and aminoiodination, see: (a) Y. Cai, X. Liu, Y. Hui, J. Jiang, W. Wang, W. Chen, L. Lin and X. Feng, Angew. Chem., Int. Ed., 2010, 49, 6160; (b) L. Zhou, J. Chen, C. K. Tan and Y.-Y. Yeung, J. Am. Chem. Soc., 2011, 133, 9164; (c) Y. F. Cai, X. H. Liu, J. Li, W. L. Chen, W. T. Wang, L. L. Lin and X. M. Feng, Chem.-Eur. J., 2011, 17, 14916; (d) A. Alix, C. Lalli, P. Retailleau and G. Masson, J. Am. Chem. Soc., 2012, 134, 10389; (e) D. Huang, X. Liu, L. Li, Y. Cai, W. Liu and Y. Shi, J. Am. Chem. Soc., 2013, 135, 8101; (f) C. S. Brindle, C. S. Yeung and E. N. Jacobsen, Chem. Sci., 2013, 4, 2100; $(g)$ F. Chen, C. K. Tan and Y.-Y. Yeung, J. Am. Chem. Soc., 2013, 135, 1232. For mechanistically related asymmetric olefin sulfenofunctionalization, see: $(h)$ S. E. Denmark and H. M. Chi, J. Am. Chem. Soc., 2014, 136, 8915; (i) S. E. Denmark, E. Hartmann, D. J. P. Kornfilt and H. Wang, Nat. Chem., 2014, 6, 1056. 
4 For existing asymmetric olefin aminochlorination methods, see: (a) Y. F. Cai, X. H. Liu, J. Jiang, W. L. Chen, L. L. Lin and X. M. Feng, J. Am. Chem. Soc., 2011, 133, 5636; (b) M. T. Bovino and S. R. Chemler, Angew. Chem., Int. Ed., 2012, 51, 3923; (c) Y. Cai, X. Liu, P. Zhou, Y. Kuang, L. Lin and X. M. Feng, Chem. Commun., 2013, 49, 8054.

5 For catalytic olefin aminohydroxylation that proceeds through an iron-nitrenoid intermediate, see: (a) G.-S. Liu, Y.-Q. Zhang, Y.-A. Yuan and H. Xu, J. Am. Chem. Soc., 2013, 135, 3343; (b) Y.-Q. Zhang, Y.-A. Yuan, G.-S. Liu and H. Xu, Org. Lett., 2013, 15, 3910; (c) D.-F. Lu, C.-L. Zhu, Z.-X. Jia and H. Xu, J. Am. Chem. Soc., 2014, 136, 13186.

6 D.-F. Lu, G.-S. Liu, C.-L. Zhu, B. Yuan and H. Xu, Org. Lett., 2014, 16, 2912.

7 (a) T. Bach, B. Schlummer and K. Harms, Chem. Commun., 2000, 287; (b) T. Bach, B. Schlummer and K. Harms, Chem.-Eur. J., 2001, 7, 2581; (c) H. Danielec, J. Klügge, B. Schlummer and T. Bach, Synthesis, 2006, 551.

8 See ESI $\dagger$ for details of substrate synthesis. Acyloxyl carbamates are reactive, while tosyloxyl and alkoxyl carbamates are non-reactive and fully recovered under the reaction conditions.

9 The relative stereochemistry of $2 \mathbf{a}$ was determined by comparison of the experimental NMR data with those reported in ref. 7. It was further corroborated by ${ }^{1} \mathrm{H}$ NMR and X-ray crystallographic analysis of a structural analog of 2a. See ESI $\dagger$ for details.

10 The relative stereochemistry was assigned based on the ${ }^{1} \mathrm{H}$ NMR and X-ray crystallographic analysis of a structural analog described in ref. 6; see ESI $\uparrow$ for details.

11 Complementary stereochemistry was achieved (in entry 15 of Table 2) compared with the known method reported in ref. 7, where the syn-aminochlorination product was isolated. This substrate did not undergo kinetic resolution with a chiral catalyst, the complex $\mathrm{Fe}\left(\mathrm{NTf}_{2}\right)_{2}-\mathbf{L 5}$. Both the starting material and product were isolated as racemates.

12 For leading references on chiral BOX and related ligands, see: (a) D. A. Evans, K. A. Woerpel, M. M. Hinman and M. M. Faul, J. Am. Chem. Soc., 1991, 113, 726; (b) H. Nishiyama, Y. Itoh, H. Matsumoto, S.-B. Park and K. Itoh, J. Am. Chem. Soc., 1994, 116, 2223; (c) Y. Nishikawa and H. Yamamoto, J. Am. Chem. Soc., 2011, 133, 8432.

13 The absolute stereochemistry of 2 a was determined by X-ray crystallographic analysis of a structural analog of $\mathbf{2 a}$. See $\mathrm{ESI} \uparrow$ for details.

14 For detailed procedure and HPLC traces of $\mathbf{4}$, see ESI. $\dagger$

15 For the synthesis of $\mathbf{L 9}$, see ref. 6.

16 The iron-L5 complex catalyzed the reaction favoring the synaddition product ( $\mathrm{dr}$ (anti/syn): $0.47: 1$ ); ee for the antiaddition product was $60 \%$ and ee for the syn-addition product was $<5 \%$. The relative stereochemistry was assigned based on the ${ }^{1} \mathrm{H}$ NMR and X-ray crystallographic analysis of a structural analog described in ref. 6; see $\mathrm{ESI}^{\dagger}$ for details.

17 When a chloroacetyl group was used as the activating group, a different result was obtained. For details, see entry 8 of Table 3.

18 For an example of stepwise atom transfer reactions with different reaction profiles for cis/trans isomeric olefins, see: N. H. Lee and E. N. Jacobsen, Tetrahedron Lett., 1991, 32, 6533.

19 For the oxidation of a radical species by a high-valent metal through ligand transfer or electron transfer, see: (a) M. S. Kharasch and G. Sosnovsky, J. Am. Chem. Soc., 1958, 80, 756; (b) J. K. Kochi, Science, 1967, 155, 415. For a relevant enzymatic $\mathrm{C}-\mathrm{H}$ chlorination reaction of hydrocarbons catalyzed by iron-containing metalloenzymes, see: (c) F. H. Vaillancourt, J. Yin and C. T. Walsh, Proc. Natl. Acad. Sci. U. S. A., 2005, 102, 10111. 